\title{
The Practice of On-line Learning in Higher education: Prospects and Challenges for Ukraine
}

\author{
Bohdana Melnyk \\ Student, Lviv Polytechnic National University, Lviv, Ukraine
}

\begin{abstract}
.
The idea of the paper is to briefly describe the practice of online learning and its implementation in educational process taking into account its challenges and constraints. Education systems all over the world including Ukraine are facing the necessity to reconsider learning and teaching paradigm and accommodate it to digital education environment. Among the features of online learning, we may identify student-centered approach, close student-student, teacher-student and content-student interaction, its wide availability and flexibility, co-creation, the opportunity to upgrade one's self-assessment and critical thinking skills, the choice to join either synchronous or asynchronous online courses due to the individual life and working schedules, blended learning opportunities, instantaneous feedback on students' performance, high level of digital literacy and etiquette to meet present requirements towards teaching and learning online. Challenges for Ukraine may include the urgency of teacher training, a new design of online courses, the necessity to educate students and teachers in terms of digital literacy and etiquette, the availability of high-speed Internet in remote areas, and implementation of new approaches to teaching and learning. Another challenging aspect of learning via the Internet is that a person may feel herself isolated, which may cause certain psychological problems. Making the first steps in the direction of reorganization of higher education system, the world community should also think about the consequences, learning online may draw.
\end{abstract}

Keywords: online learning, interaction and co-creation, synchronous and asynchronous courses, student-centered learning, deep learning

\section{Introduction}

Nowadays, the world is becoming more and more digitalized. There are diverse factors that are contributing to this. Among them are continuous development of modern technologies and the pandemic that have influenced much the way people communicate and render services. Educational service is not an exclusion. Higher educational institutions have to accommodate to the present situation where teaching and learning are being transferred to the Internet. Digitalization of education started almost 30 years ago and has been developing rapidly. Now, there are plenty of teaching and learning materials available online, electronic libraries, online dictionaries and translation services, webinars and online conferences, social media resources, interactive platforms to deliver classes online, and virtual learning 
environments with the opportunity to obtain instantaneous feedback on students' performance. Notwithstanding the fact that all these tools and activities are extremely comfortable to use, they have had a supplementary role in the educational process so far. They have been supplements to an on-site class and face-to-face communication between a teacher and students. However, now academic community is facing a new era of education due to COVID-19 and its consequences. Online learning has become the most popular form of distant education nowadays. The focus of the article is to dwell upon the practice of online education with the purpose to identify its potential and prospects of its development within the Ukrainian higher education system.

\section{Body of paper}

J. Stern in his paper "Introduction to Online Teaching and Learning" states that the new paradigm of online education is based upon the theory of constructivism presented by the Swiss philosopher J. Piaget. The theory suggests that students may learn while interacting with the environment (2000). This presupposes student-centered approach which means that the whole educational process is based upon the active position and motivation the learner has towards the discipline. The teacher stops being "the master" and starts being "the advisor" to help the learner find the most comfortable learning environment. Student-centered approach presupposes individual approach to every learner, responsibility every learner has for the results obtained, development of social competence, relevance of the learner's background, high achievement level, co-creation between the learner, the advisor and the task itself (2000).

An obvious advantage of online learning is its availability. No matter how far the educational institution they have chosen is from the student's place of residence, they may apply for any course they wish and get necessary training. We may than characterize online education as cross-border education which means that the world is becoming closer in educational perspective, which makes education flexible and attainable for everybody. Ukrainian higher educational institutions are on the way to introduce both, synchronous and asynchronous online courses. The former enables students to participate in a course from a distance in a real time according to the time-table suggested by the university, while the latter allows them to arrange their learning hours in the most suitable way due to certain time constraints they may have: some students may have full-time jobs or they just prefer to work independently. Thus, asynchronous learning is organized for students to manage their time effectively. They are usually supplied with an amount of content relevant to the course and a range of activities to complete; and a comfortable learning environment students choose and free access to a computer make online learning really appealing. However, blended learning is more widespread in higher educational institutions of Ukraine. It presupposes both, online and on-site classes. The reasons blended learning is popular are numerous. For instance, it's suitable for the learners who would like to limit their attendance to the actual number of classes they can physically attend due to certain circumstances they have. However, these learners prefer live communication with the teacher and would not like to feel lonely studying from home being separated from their academic group. Among the pros of blended learning is the availability of hands-on studying opportunities which is ultimate for applied courses, such as chemistry or archeology. 
Having been struck by the pandemic of 2020, world academic community has been doing its best to tune training to minimize the negative impact of it. Digital literacy has become an integral part of educational sphere nowadays. Online learning allows both, teachers and students acquiring information competence to be able to effectively participate in educational process. It does not mean profound knowledge in IT, it is rather a mixture of critical thinking, social engagement and digital tool knowledge. When it comes to digital literacy, it comes to deep learning and the skills it demands from a student, namely:

- critical thinking: being able to evaluate information and arguments, identify connections and construct meaningful knowledge;

- collaboration: being able to demonstrate interpersonal and team-related skills;

- creativity: being able to think out-of-the-box;

- communication: being able to communicate to a variety of audiences;

- character: the desire to make learning a part of living (2017).

Online learning requires adequate self-assessment and allows quick feedback on students' performance form the side of the teacher. Being active members of educational process, students strive for the best results. They are not time-framed or limited to a particular mode of performing any task. Creative solution to a problem is the one that matters in online education process. The teacher should provide the learners with the opportunity to analyze the outcomes of their activity and not just give a point or a mark for the task completed and submitted in time. Students have to reflect on the activity they have done, understand their weak points and strengths, work out an individual strategy for effective learning encouraged and motivated by the teacher to strive for more. Case studies, team projects, online discussions to find an alternative decision to solve a problem, virtual presentations may greatly contribute to the development of students' self-assessment skills. When a learner becomes an active member of a team with the purpose to complete the task and disseminate the results, they may watch their peers being engaged in the same activity, however, probably making more effective decisions and producing more successful outcomes. This fact may both motivate and discourage the learner; thus, the teacher's role as an advisor is to make learners continuously motivated. Assessment and feedback are to be based on observations of how a student behaves in different learning environment and copes with diverse tasks. Games may also greatly contribute to assessing students' knowledge in e-learning. Different competitions, puzzles, short movie role-plays, reality testing may help teachers to evaluate the amount of knowledge and skills relevant to the topic. However, the essential thing is not to discourage the learner by giving extremely sophisticated tasks: more interesting and challenging and less complicated. Continuous negative result might be disastrous, and any inspiration a learner has for the course may disappear. So, organizing an online course, a teacher should demand much challenge but leave the learner satisfied, help solve problems and develop strategies, set strict goals and objectives for each activity, train to think, analyze, summarize and make conclusions, keep learners interested and excited (2021)

Speaking about challenges induced by the necessity to transfer to online courses in Ukrainian higher educational institutions, we may identify the following:

- organizing teacher training for online teaching

- implementing new approaches in teaching and learning

- introducing virtual learning environment 
- providing perfect Internet connection even in the most remote territories of the country

- reorganizing the design of an online course

- educating students in terms of digital etiquette

Teacher training is directly related to the outcomes and the methods that should be applied in the new perspective. Those teachers who have little experience or no experience at all in online teaching said that the main difficulties arise from the complexity of the instructional situation (Ocak, 2011). Actually, Ukrainian teachers have not got any training and started working online with students applying the same methodology they were applying during inclass training. Nowadays teacher training is basically held in the forms of webinars or online conferences. In perspective, close attention should be paid to providing continuity of online learning. Teachers should set clear objectives of the course and share their expectations with students, supply the students with all the necessary materials (via email or social networks), demonstrate the list of assignments to be completed by the end of the course, acquaint the students with the assessment system, and, most importantly, provide the students with information on how online training will continue in case there are technical difficulties like poor internet connection, or other constraints that may deprive students of the opportunity to attend an online class. It's vital that teachers should think how they will get in touch with the students, how the students may reach a teacher, and how the materials are going to be distributed among them. Not less important is to manage students' teamwork and communication online and off-line. Teachers should choose the tasks which may demand students' collaboration and a substantial amount of individual work to be completed at home in case the class is interrupted or the timing has not been managed properly. Speaking about the timing, it should be arranged according to a strict or a flexible timetable depending upon students' needs. However, it is not correct to substitute an online class with a portion of individual work, i.e., to overload a student with individual tasks, because online learning presupposes close interaction, group thinking and decision making. In general, an effective strategy for the teacher to start accommodating to online teaching is to be alert to what students need, keep asking and make them articulate their needs, facilitate the way students share experiences (private chatrooms without teacher access), shift attention from the "prescribed content" to what students are actually doing, allow self-paced learning and reflection, guarantee student-centered design of the class, provide accurate feedback and correction of individual work (Rapanta et al., 2020)

Student-centered approach is being implemented in Ukrainian universities; however, the challenges are that the influence of the post-soviet authoritarian manner of teaching is still present and may need quite a long period of time to reconfigure. What is more, most students and teachers got used to the roles of "a subordinate" and "a boss" in the classroom, and the new role of "a co-worker" may be learned with certain difficulties. Collaboration is the key word to characterize online learning. The teacher should not focus on the information he or she considers important for students. It's advisable to take into account the student's point of view and concentrate upon the experience students want to acquire and the results they want to achieve.

The way of constructing the design of an online course becomes another challenge to take into account. The essence of an online course is the organization of learning activities in the way for the students to reach positive learning outcomes (Carr-Chellman et al., 2000). A 
mixture of design approaches should be applied, namely: synchronous, asynchronous, online, offline (Rapanta et al., 2020). Teacher presence is no less important issue to consider. Scientists believe that there are three types of teacher presence during the class: "a cognitive presence focuses on students' preparedness for the class to participate in online experience; a social presence refers to social communication channels that teachers open to enhance student-student and student-teacher interaction; a facilitatory presence which is teacher's instruction, discourse and mentoring activities" (Anderson et al., 2001). The idea is that during online classes the teacher should not diminish his role. The role is becoming even more sophisticated because the focus of the process is not to deliver the subject content to the receiver (the student), but to make him aware of his needs and help him find the tools to accommodate the content to the needs he has.

To facilitate online training and provide quick feedback on performance, Ukrainian universities have introduced virtual learning environments - interactive online platforms designed to provide learners with the opportunity to get acquainted with the curriculum, work plans, tasks and activities relevant to the course. Students can do tests, exercises, quizzes, and get instantaneous feedback on their performance. There is also an opportunity for the teachers to share materials and leave comments concerning the work performed.

Close attention is to be paid to digital etiquette as an integral part of effective online communication. Every learner has to understand that positive outcomes of educational process fully depend on his or her honesty and integrity. Online training makes students be accountable for the results they obtain. There is no direct control from the side of a teacher, and learners should reflect upon every activity they perform. This makes them focused, responsible and critical towards their actions. However, there is a number of learners who are not prepared for self-education and still need a guide to make them more concentrated upon the objective. Such learners simply need more time to accommodate to challenging learning conditions we are facing nowadays and become aware of a strong necessity to meet new demands towards a new generation of professionals ready to share their knowledge and expertise. In general, digital etiquette has much in common with a regular etiquette: decency, openness and desire to cooperate are always praised.

\section{Conclusion}

All in all, online learning can be considered rather controversial form of education. On the one hand, it introduces innovative teaching methods with the student being the center of the educational process, facilitates communication and distribution of materials online, creates diverse learning environments, activates passive learners who may express themselves more confidently studying from home, makes learning process more convenient through accommodating busy schedules students and teachers have, and guarantees deep learning encouraging students to think creatively and critically. But, on the other hand, it has become a huge challenge for those who need social engagement, live communication and feeling of being a part of the community. There are many problems to be solved concerning the implementation of online learning strategies, however the first steps are being taken. 


\section{Acknowledgment}

This paper is an output of the individual research task I have been given to dwell upon the issues of online learning and its perspective implementation in Ukraine with the purpose to demonstrate the results of my research at an international scientific conference.

\section{References}

1. Anderson, T., Rourke 1., Garison, D.R., and Archer, W. (2001). Assessing teacher presence in a computer conferencing context. Journal of Asynchronous Learning Networks, 5(2), 1-17. https://doi.org/10.24059/olj.v5i2.1875

2. Carr-Chellman, A., Duchastel, P. (2000). The ideal online course. British Journal of Educational Technology, 31(3), 229-241. https://doi.org/10.1111/14678535.00154. Return to ref 2000 in article

3. Ocak, M,A, (2011). Why are faculty members not teaching blended courses? Insights from faculty members. Computers and Education, 56(3), 689-699. https://doi.org/10.1016/j.compedu.2010.10.011

4. Rapanta, C., Botturi, 1., Goodyear, P. et al. (2020). Online University Teaching During and after COVID-19 Crisis: Refocusing Teacher Presence and Learning Activity. Postdigit Sci Educ 2, 923-945. https://doi.org/10.1007/s42438-020-00155-y

5. https://resourced.prometheanworld.com/digital-literacy-classroom-important/

6. https://www.shiftelearning.com/blog/ways-to-assess-your-students-in-elearning

7.https://www.researchgate.net/publication/324821090_ONLINE_TEACHING_AND_LE $\underline{\text { ARNING }}$ 